\title{
Primary prostate cancer cultures are models for androgen-independent transit amplifying cells
}

\author{
PATRICK BÜHLER ${ }^{1}$, PHILIPP WOLF ${ }^{1}$, ARNDT KATZENWADEL ${ }^{1}$, WOLFGANG SCHULTZE-SEEMANN ${ }^{1}$, \\ ULRICH WETTERAUER $^{1}$, NIKOLAUS FREUDENBERG ${ }^{2}$ and URSULA ELSÄSSER-BEILE ${ }^{1}$ \\ ${ }^{1}$ Department of Urology, Experimental Research Group; ${ }^{2}$ Department of Pathology, \\ University Hospital Freiburg, 79106 Freiburg, Germany
}

Received October 23, 2009; Accepted November 16, 2009

DOI: $10.3892 /$ or_00000656

\begin{abstract}
Numerous efforts exist for developing primary prostate cancer cultures for studying the biology of this tumor entity and for evaluation of the effectiveness of novel therapies. However, there is doubt if cultures that represent the fully differentiated phenotype can be established. The aim of the present study was to characterize primary outgrowing prostate epithelial cells due to their basal or luminal characteristics and their potential for serving as androgen-responsible model. From fresh prostate cancer radical prostatectomy specimens, pieces of $~ 2-4$ mm diameter were placed on top of transwell culture chambers, which were coated with matrigel and cultured in prostate epithelial selection medium with $10 \%$ fetal calf serum. The monolayer of outgrowing cells was incubated with a physiological concentration of $1 \mathrm{nM}$ dihydrotestosterone (DHT). One group was additionally cultivated without DHT and another group was treated with the 5- $\alpha$-reductase-inbitors MK-368 and MK-905. From the monolayer of the outgrowing cells, RNA was isolated and the expression of androgen receptor (AR), prostate-specific antigen (PSA), Kallikrein 2 (KIK2), prostate-specific membrane antigen (PSMA), and prostate stem cell antigen (PSCA), cytokeratin (CK)5, and CK18 was determined by realtime quantitative PCR. The outgrowing cells from the prostate cancer tissue pieces could be characterized as epithelial cells with basal and transit amplifying characteristics as shown by co-expression of CK5 and CK18. In all cultures, a very low expression of the luminal cell marker genes AR, PSA and KLK2 was measured. The levels of PSCA were clearly higher with a broad variation. Upon cultivation without DHT or treatment with $\alpha$-reductase inhibitors no regulation of AR, PSA and K1K2 was found. Due to the co-expression of basal
\end{abstract}

Correspondence to: Dr U. Elsässer-Beile, Department of Urology, Experimental Research Group, University of Freiburg, Breisacher Str. 117, 79106 Freiburg, Germany

E-mail: ursula.elsaesser@uniklinik-freiburg.de

Key words: prostate cancer cultures, cytokeratin, androgen receptor, androgen relevant genes, basal cells, luminal cells, transit amplifying cells and luminal marker genes, primary prostate cancer cultures can be charaterized as models of transit amplifying cells of the prostatic epithelium. They do not represent the differentiated secretory androgen-responsive cell phenotype.

\section{Introduction}

Historically, in vitro cultures of human prostatic cells have been limited in availability and scope compared to those from various other organs. Therefore, three spontaneously established cell lines, PC3, DU145 and LNCaP and sublines thereof are by far the most commonly used cell culture models in prostate cancer research. However, they were all derived from metastases and therefore do not span the range of prostate cancer phenotypes and in particular are not representative of primary adenocarcinomas (1). For these reasons, primary cultures of malignant prostatic cells and their normal epithelial counterparts are intensively sought.

A variety of substantially similar methods are available to etstablish primary cultures of prostatic epithelial cells derived from benign or malignant tissues. Tissues are typically disaggregated mechanically or with enzyme cocktails. Then small clumps are inoculated into dishes containing specialized media and cultured or co-cultured with stromal cells (2). Although there was controversity about the relevance as secretory cell phenotype, these models were frequently used for characterizing prostate cancer growth and gene expression (3).

The goal of the present study was to establish and characterize primary prostate cancer cultures with respect to their utility as androgen-relevant model.

\section{Materials and methods}

Tumor tissues. Tumor tissue was obtained with informed consent from 33 patients with histologically verified primary prostate carcinomas undergoing radical prostatectomy at the Department of Urology, University Hospital of Freiburg. None of these patients had received preoperative antitumor therapy. The grading of the tumors was Gleason $6(n=3)$, Gleason 7 $(n=15)$, Gleason $8(n=12)$, Gleason $9(n=2)$ and Gleason 10 $(n=1)$. Under pathologic direction, tumor areas were sectioned. From all sides of the samples a small piece was embedded in paraffin for determination of the tumor content on hematoxylin and eosin (H\&E) sections. 
Table I. Primer and probe sequences used in the real-time RT-PCR.

\begin{tabular}{|c|c|c|}
\hline Gene & Primer sequences $\left(5^{\prime}-3^{\prime}\right)$ & Hydrolysis probe sequences $\left(5^{\prime}-3^{\prime}\right)$ \\
\hline CK5 & $\begin{array}{l}\text { cggttggcaatctcctcatac } \\
\text { cggttggcaatctcctcatac }\end{array}$ & 6-Fam-accgcaacctggacctggatagcat-Tamra \\
\hline CK18 & $\begin{array}{l}\text { ggctccgcaaggtcattg } \\
\text { gctggcaatctgggcttg }\end{array}$ & 6-Fam-ttacttcctcttcgtggttcttcttcat-Tamra \\
\hline KLK2 & $\begin{array}{l}\text { ccatagagattcacagcccagag } \\
\text { cccaccgtcttgttactataaagc }\end{array}$ & 6-Fam-tgcctctaacagtccttgcttcttcaca-Tamra \\
\hline PSCA & $\begin{array}{l}\text { ggccatataaagtcacctgagg } \\
\text { gccaagcctgccatcaac }\end{array}$ & 6-Fam-agcagcacagccttcatggtcact-Tamra \\
\hline AR & $\begin{array}{l}\text { tgtcacacattgaaggctatgaa } \\
\text { ggctggttgttgtcgtgtc }\end{array}$ & 6-Fam-cacactacacctggctcaatggcttcc-Tamra \\
\hline KLK3 & $\begin{array}{l}\text { atgaagcactgagcagaagc } \\
\text { caggacagagtgggttatgttt }\end{array}$ & 6-Fam-acaacgcaccagacactcacagcaag-Tamra \\
\hline PSMA & $\begin{array}{l}\text { cagcgtggaaatatcctaaatctga } \\
\text { cacgcetataagcatattcatttgc }\end{array}$ & 6-Fam-tggtgcaggagaccctctcacacca-Tamra \\
\hline GAPDH & $\begin{array}{l}\text { gacctgacctgccgtctag } \\
\text { gcccaggatgccettgag }\end{array}$ & 6-Fam-tccgacgcetgcttcaccacct-Tamra \\
\hline
\end{tabular}

Primary cell cultures. Cultivation of explants was performed on semi-permeable polyethyleneterephthalate (PET) membranes as growth surface, which are part of special inserts in 6-well companion plates (Becton-Dickinson, Heidelberg, Germany). The growth area of one insert was $4.2 \mathrm{~cm}^{2}$. The inserts were first coated with extracellular matrix, which was diluted 1:20 with PBS according to the manufacturer's protocol (Matrigel, Collaborative Research, Inc., Bedford, MA).

The fresh tumor specimen were cut into small pieces (2-4 $\mathrm{mm}$ in diameter). Five pieces were placed on each insert and covered with prostate epithelial selection medium (PREGM, Cambrex, East Rutherford, NJ) supplemented with $2 \%$ fetal calf serum (FCS). The inner compartment of the culture chamber was filled with $2 \mathrm{ml}$ DMEM supplemented with $10 \%$ FCS and a physiological concentration of $1 \mathrm{nM}$ DHT. In separate cultures of the same tissue samples, the 5 - $\alpha$-reductase inhibitors MK906 and MK386 at $10 \mu \mathrm{M}$ (kindly provided by MSD Sharp \& Dohme, Haar, Germany) were added instead of DHT or DHT was omitted. Then the companion plate was incubated in a humidified atmosphere of $5 \%$ carbon dioxide. When the outgrowing cells formed a monolayer around the tumor pieces, medium was changed regularly. After about three weeks the insert membranes were covered with outgrowing cells. Then the cells were harvested by incubation with cell dissociation solution (Sigma, Deisenhofen, Germany) for $1 \mathrm{~h}$. The cells were washed twice with PBS and the number of viable and dead cells was quantified by trypan blue incorporation.

cDNA synthesis from template RNA. Total RNA from $1 \times 10^{5}$ cells was isolated with silicagel-based membranes (RNeasy, Qiagen, Hilden, Germany) according to the manufacturer's protocol. cDNA synthesis was performed at $42^{\circ} \mathrm{C}$ for $60 \mathrm{~min}$ in a final volume of $100 \mu 1$ which contained $50 \mu 1$ of denatured RNA, $20 \mu 1$ 5X buffer (Promega, Heidelberg, Germany), $5 \mu 1$ dNTP-Mix (dATP, dCTP, dGTP, dTTP, Promega), $1.5 \mu 1$ RNAsin (40 U/ $\mu 1$, Promega) $2.5 \mu 1150 \mathrm{pM}$ random hexamer primers and $2.5 \mu \mathrm{l}$ AMV reverse transcriptase $(10 \mathrm{U} / \mu 1$, Promega).

Real-time quantitative PCR. Thermocycling for each reaction was performed in a final volume of $10 \mu 1$ containing $4 \mu 1$ of cDNA template, $0.2 \mu 1$ of each sense and antisense primer (250 pM), $0.4 \mu 1$ probe (10 pM), $5 \mu 1$ light Cycler 480 Probe Master Mix (Roche Diagnostics, Mannheim, Germany) and $0.2 \mu \mathrm{l}$ ultrapure water. After $4 \mathrm{~min}$ of initial denaturation at $95^{\circ} \mathrm{C}$, the cycling conditions of 45 cycles for each gene consisted of denaturation at $95^{\circ} \mathrm{C}$ for $10 \mathrm{sec}$, annealing at $60^{\circ} \mathrm{C}$ for $30 \mathrm{sec}$, elongation at $72^{\circ} \mathrm{C}$ for $1 \mathrm{sec}$ and a final cooling step to $40^{\circ} \mathrm{C}$ for $10 \mathrm{sec}$. GAPDH (glycerinaldehyde-3phosphate-dehydrogenase) was used as reference gene. The standard curves for all genes were prepared with an LNCaP template at dilutions of 1:10,1:100,1:1000 and 1:10000. The PCR reactions were performed in a Light Cycler 480 Instrument (Roche Diagnostics). Experiments were prepared in duplicates for each data point. The relative gene expression was normalized on the basis of the expression of the LNCaP standard curve (abssolute quantification values). Finally, the expression of each gene was normalized to the expression of the gene GAPDH. Primer and probe sequences for the genes determined are given in Table I.

\section{Results}

Morphological characterization of outgrowing cells in primary cultures. Cell cultures were prepared from 33 prostate cancer 
A

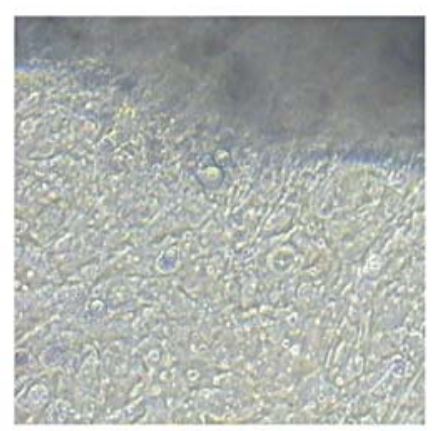

B

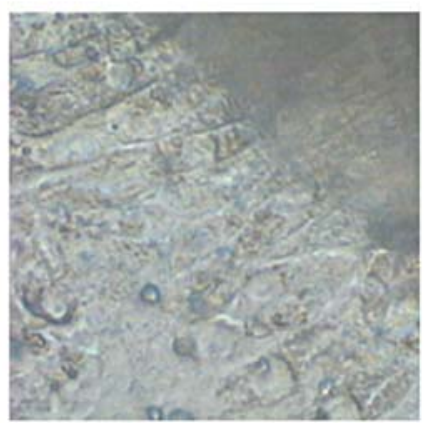

C

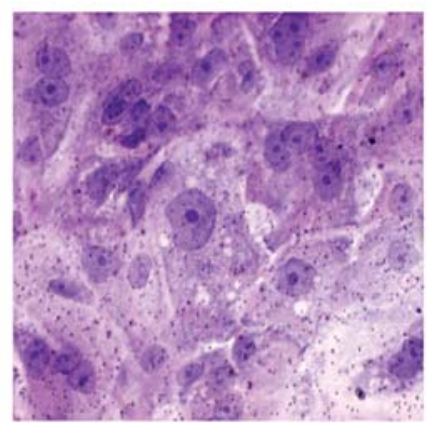

Figure 1. Photomicrograph of primary outgrows from PCa organoids after 2 weeks of culture. A monolayer of regular polygonal epithelial cells is visible in phase contrast images at x10 (A) and x40 (B) magnification. H\&E staining (C) shows the cells of the outgrowth with typical morphological characteristics for the epithelial phenotype with prominent nucleoles.

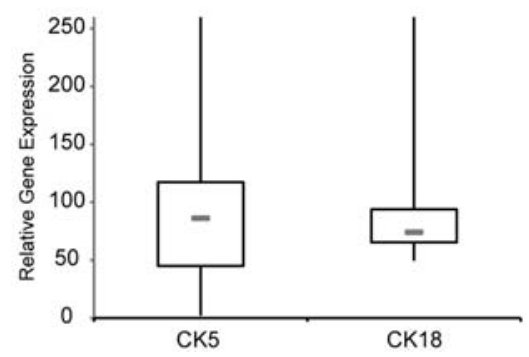

Figure 2. Relative expression of CK5 and CK 18 mRNA in primary cultures of 33 prostate cancer tissue samples. Data are shown as box plots.

tissue specimens, which were confirmed to contain $>70 \%$ cancerous tissue by the adjacent surrounding histology. In all cases, the organoids attached within 2-5 days and cellular outgrowths could be observed. Morphological assessment demonstrated cuboidal cells forming polygonal colonies of various grades of architecture, mostly orderly distributed as monolayer (Fig. 1). The cell proliferation in the cultures differed in the individual tumor samples, without correlation to the tumor content or Gleason score. However, the size of the organoids influenced cell growth in as far as the outgrowth from small tissue pieces was slower. The monolayer of one insert $\left(4.2 \mathrm{~cm}^{2}\right)$ usually consisted of $5 \times 10^{5}$ to $5 \times 10^{6}$ viable cells.

Determination of cytokeratins as basal or luminal markers. For determination of the basal or luminal phenotype of the outgrowing cells a quantitative real-time PCR was run. Specific primers were used for CK5 as basal cell marker and CK18 as marker for luminal cells. In all cultures expression of both CK5 and CK18 was found in a wide range. Data are shown as box plots in Fig. 2

Expression of PSCA in the primary cell cultures. According to Tran et al (4) who suggested PSCA to be a marker of late
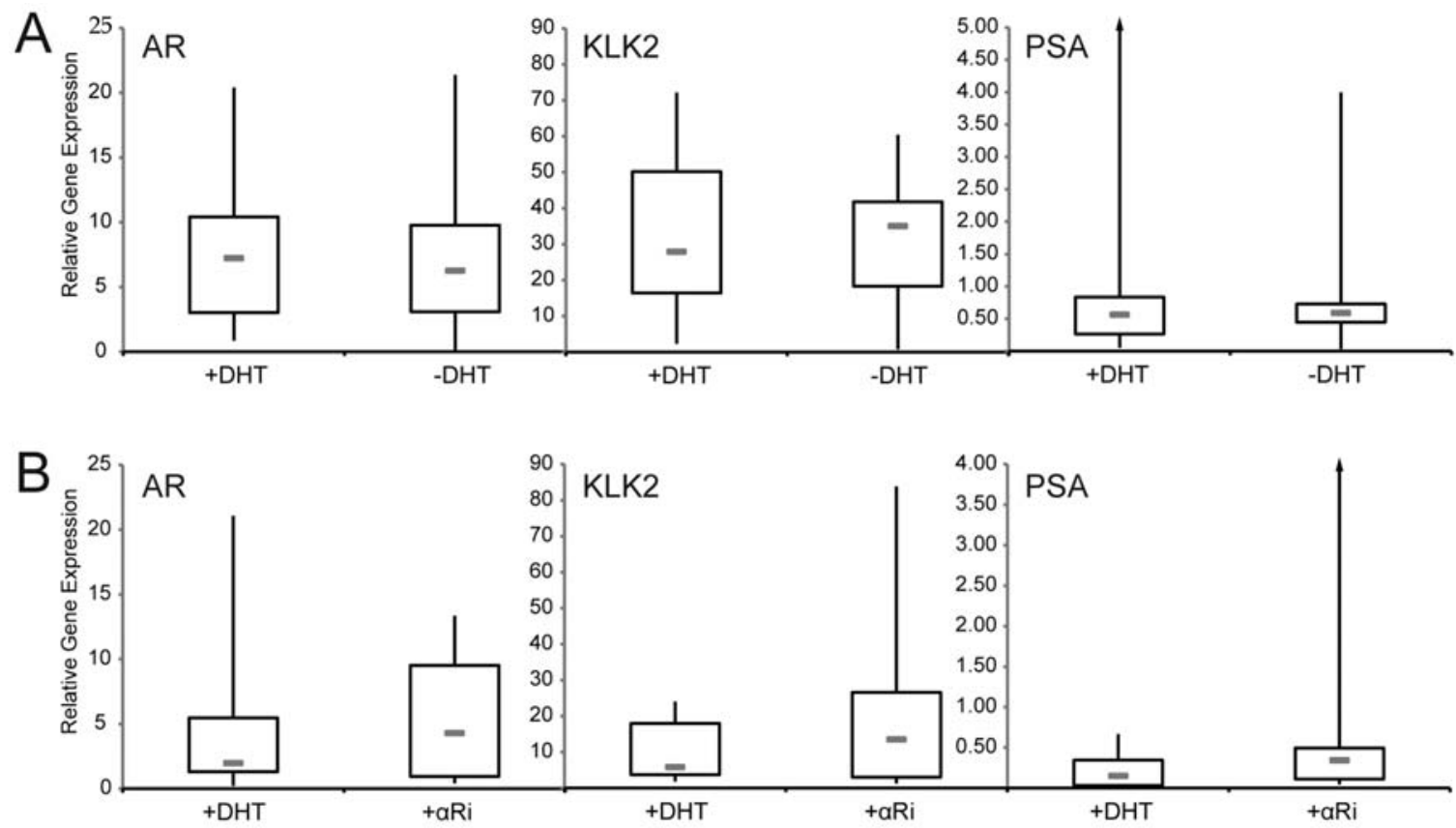

Figure 3. Comparison of the relative mRNA expression of AR, PSA and K1K2 in a) primary cultures treated either with or without DHT at 1 nM b) in primary cultures treated either with DHT at $1 \mathrm{nM}$ or the $\alpha$-reductase-inhibitors $(\alpha \mathrm{Ri})$ MK906 and MK386 at $10 \mu \mathrm{M}$. Data are shown as box plots. 
Table II. Relative mRNA expression values of AR, PSA, KLK2, PSMA, PSCA, CK5 and CK18 in primary prostate cancer cultures of tissues from 33 patients treated with $1 \mathrm{nM}$ DHT.

\begin{tabular}{|c|c|c|c|c|c|c|c|c|c|}
\hline Patient & Gleason & Tumor content & AR & PSA & KLK2 & PSMA & PSCA & CK5 & CK18 \\
\hline 1 & $7(3+4)$ & + & 9.34 & 0.98 & 72.15 & 0.23 & 558 & 93.1 & 66.2 \\
\hline 2 & $6(2+4)$ & ++ & 6.75 & 0.24 & 15.35 & 0.40 & 2000 & 120.2 & 62.6 \\
\hline 3 & $7(3+4)$ & ++ & 13.52 & 0.58 & 55.08 & 0.24 & 14900 & 108.8 & 92.5 \\
\hline 4 & $8(5+3)$ & ++ & 2.49 & 0.77 & 54.27 & 0.43 & 300 & 28.6 & 65.1 \\
\hline 5 & $7(4+3)$ & + & 10.33 & 2.87 & 21.86 & 26.84 & 14800 & 65.0 & 266.1 \\
\hline 6 & $6(2+4)$ & ++ & 7.70 & 0.85 & 60.85 & 0.29 & 24900 & 125.3 & 49.5 \\
\hline 7 & $7(3+4)$ & ++ & 4.66 & 0.50 & 27.28 & 0.12 & 4100 & 61.8 & 71.7 \\
\hline 8 & $8(3+5)$ & ++ & 1.88 & 0.61 & 37.84 & 0.09 & 300 & 39.5 & 104.0 \\
\hline 9 & $7(3+4)$ & ++ & 16.25 & 0.55 & 28.59 & 0.39 & 900 & 86.9 & 80.5 \\
\hline 10 & $8(3+5)$ & ++ & 10.44 & 0.23 & 13.68 & 0.15 & 100 & 33.6 & 69.5 \\
\hline 11 & $7(3+4)$ & ++ & 5.24 & 0.36 & 19.70 & 0.24 & 10 & 85.6 & 94.3 \\
\hline 12 & 8 & + & 20.42 & 14.10 & 31.75 & 47.99 & 60 & 2.2 & 166.6 \\
\hline 13 & $7(3+4)$ & ++ & 0.86 & 0.05 & 2.56 & 0.14 & 150 & 259.8 & 76.5 \\
\hline 14 & $8(4+4)$ & ++ & 1.11 & 0.06 & 2.34 & 0.10 & 1700 & 205.8 & 54.2 \\
\hline 15 & $6(3+3)$ & + & 1.31 & 0.11 & 3.70 & 0.15 & 0 & 150.6 & 74.2 \\
\hline 16 & $8(3+5)$ & + & 1.97 & 0.03 & 2.68 & 0.24 & 0 & 107.4 & 74.5 \\
\hline 17 & $7(3+4)$ & ++ & 0.21 & 0.03 & 1.83 & 0.06 & 0 & 139.4 & 72.7 \\
\hline 18 & $8(4+4)$ & ++ & 0.69 & 0.03 & 3.79 & 0.31 & 0 & 109.5 & 79.7 \\
\hline 19 & $7(3+4)$ & + & 5.46 & 0.15 & 5.82 & 0.15 & 158 & 157.6 & 44.1 \\
\hline 20 & $7(3+4)$ & + & 7.43 & 0.19 & 11.50 & 0.46 & 85 & 84.8 & 54.5 \\
\hline 21 & $8(4+4)$ & ++ & 21.07 & 0.34 & 17.96 & 0.44 & 145 & 145.4 & 56.4 \\
\hline 22 & $8(4+4)$ & ++ & 5.08 & 0.54 & 24.06 & 0.17 & 129 & 128.7 & 130.3 \\
\hline 23 & $7(3+4)$ & + & 1.65 & 0.67 & 21.98 & 0.29 & 95 & 94.5 & 65.4 \\
\hline 24 & $7(4+3)$ & + & 3.70 & 0.61 & 58.69 & 0.53 & n.d. & 38.0 & 60.1 \\
\hline 25 & 10 & ++ & 5.90 & 0.24 & 19.78 & 0.05 & n.d. & 29.4 & 23.2 \\
\hline 26 & $7(3+4)$ & ++ & 2.12 & 0.27 & 9.27 & 0.12 & n.d. & 97.4 & 59.3 \\
\hline 27 & $9(4+5)$ & + & 282.74 & 227.23 & 1894.74 & 0.00 & n.d. & 10.0 & 0.0 \\
\hline 28 & $8(3+5)$ & ++ & 73.67 & 76.33 & 2084.11 & 2.49 & n.d. & 112.7 & 961.3 \\
\hline 29 & $8(4+4)$ & + & 5.45 & 1.87 & 20.73 & 1.11 & n.d. & 68.8 & 40.9 \\
\hline 30 & $7(3+4)$ & + & 11.47 & 0.55 & 33.45 & 0.17 & n.d. & 30.5 & 23.6 \\
\hline 31 & $7(3+4)$ & + & 8.25 & 1.00 & 25.92 & 1.03 & n.d. & 112.0 & 72.4 \\
\hline 32 & 8 & ++ & 2.78 & 1.14 & 22.33 & 1.18 & n.d. & 224.0 & 90.4 \\
\hline 33 & $9(5+4)$ & ++ & 8.62 & 0.54 & 14.90 & 1.23 & n.d. & 79.4 & 109.8 \\
\hline Median & & & 5.46 & 0.54 & 21.86 & 0.24 & 150 & 94.5 & 71.7 \\
\hline
\end{tabular}

intermediate prostate epithelial cells, we tested PSCA expression in the primary cultures. In almost all measured cultures, PSCA mRNA was present. There was a broad variation in the different cell cultures. Data are shown in Table II.

Expression of PSMA in the primary cell cultures. Expression of prostate-specific membrane antigen (PSMA) was very low in the 33 primary cell cultures tested. There was no correlation to the Gleason score of the parental tissue. Data are given in Table II.

Expression of AR, PSA and KlK2 in the primary cell cultures. AR mRNA expression was generally very low in the primary cell cultures. Additionally, the expression of the androgen- regulated genes PSA and K1K2 was low as determined by quantitative real-time PCR. The values of both genes varied highly in the different cultures. The median expression of PSA was lower compared to K1K2 (Table II).

Effects of androgen depletion in the primary cultures. In order to study the androgen-relevance of the primary cultures, we established cultures with and without $1 \mathrm{nM}$ DHT, respectively, from tissue samples of 14 patients (patients no. 1-14 in Table II). There was no difference in the groups with respect to morphology and proliferation of the outgrowing cells. The expression levels of AR and the androgen-relevant genes K1K2 and PSA were not significantly different in the treatment groups. Data are given as box plots in Fig. 3A. 
Additionally, cultures obtained from tissue samples of 9 patients (patients no. 15-23 in Table II) were treated with DHT and with the 5- $\alpha$-reductase inhibitors MK368 and MK905 respectively. Comparison of these cultures showed no difference in cell proliferation. As shown in Fig. 3B, neither expression levels of AR, nor of PSA and K1K2 showed significant alterations upon androgen depletion conditions.

\section{Discussion}

Among the most important tools which may disclose the heterogeneous properties of prostate cancer cells are in vitro culture techniques. In recent years several biological models have been developed in order to propagate prostate cancer cells from primary cancer tissues.

In most cases, small tissue samples were typically disaggregated either mechanically or with enzyme cocktails and then single cells or small clumps inoculated into dishes containing specialized media $(3,5)$. Generally, there are two problems arising with the outgrowing cells: i) no clear differentiation can be made with respect to the benign or malignant character of these cells and ii) findings about their basal or luminal secretory character are controversial.

Within the human prostatic epithelium, two major cell types are discernible, basal and luminal, which differ in their morphologies, patterns of cytokeratin expression and hormonal response. Luminal cells are characterized by the expression of CK8/CK18, and hormonal relevance, while basal cells express CK 5 and are androgen-independent (6).

For achieving a secretory phenotype in primary prostate cultures, elevated serum concentrations (7), the use of collagen gels and addition of stromal cells (8) were suggested.

Due to these suggestions, we have established a cell culture system where small tumor clumps, so-called organoids, were layered on matrigel-coated PET membranes and covered with an epithelial selection medium supplemented with FCS. Since no differentiation marker exists to discriminate malignant from benign prostate epithelial cells, samples with high pathological tumor content were chosen. Interestingly, there was no correlation between the grading of the parental tissue and the morphology of the culture or proliferation.

In our system, cells were growing faster, when the tumor pieces were relatively large. Therefore, it is suggested that the epithelial cells are supplied with growth factors from the stromal part of the organoids. The importance of stromal cells for proliferation of prostate epithelial cells was also emphasized by other authors $(9,10)$. Alternatively, these factors can be supplied by a fibroblast co-culture $(11,12)$. However, in order to have a complete autologous system, we cultured without fibroblasts.

In our cultures, the outgrowing epithelial cells expressed CK5 as basal cell marker and simultaneously CK18 as luminal cell marker as well as very low AR, PSA and KIK2, which suggests a lack of complete differentiation. Therefore, they resemble cells described as transit amplifying cells or intermediate cells (13). This corresponds to a study by Garraway et al who cultured normal prostate epithelial cells and characterized them as transient amplifying population (14). In a similar culture system, Tran et al found a subpopulation that co-expressed PSCA and CD44 as basal marker as well as AR and PSA as secretory markers. These investigators interpreted their findings as evidence of an intermediate population of cells in transition from a basal to a terminally differentiated secretory phenotype and stated PSCA as a marker of late intermediate prostate epithelial cells. Also Uzgare et al found an essentially pure population of transit amplifying cells in primary cultures from fresh prostate tissues (15).

In our system we found a minimal expression of AR and the AR-relevant genes PSA and K1K2 and no alterations upon androgen deprivation. This might be expected for transit amplifying cells, however, is in contrast to a few other published studies. Festuccia et al for instance found moderate high levels of AR, PSA and KIK2 in outgrowing cells from prostate tissue clumps (16) and a decreased cell proliferation upon treatment with 5- $\alpha$-reductase inhibitors (17). Moreover, bicalutamide was shown to decrease cell viability in a dosedependent manner (18). Nanni et al described the outgrowing cells from small prostate tissue fragments as highly enriched in the secretory luminal phenotype (19).

However, most investigators suggest that primary prostate cell cultures outgrowing from tissue express low or no AR and PSA and do not respond to androgen or respond minimally $(3,20)$. Whereas not suitable for testing androgenrelevant questions, these cultures may be useful for comparing gene expression in samples of different origin $(21,22)$.

In conclusion, based on our data it can be confirmed that primary prostate outgrowing cells from tissue organoids are models of transit amplifying cells of the prostatic epithelium. However, they do not represent the androgen-responsive secretory phenotype.

\section{References}

1. Mitchell S, Abel P, Ware M, Stamp G and Lalani E: Phenotypic and genotypic characterization of commonly used human prostatic cell lines. BJU Int 85: 932-944, 2000.

2. Peehl DM and Sellers RG: Epithelial cell culture: prostate. In: Methods of Tissue Engineering. Atala A and Lanza RP (eds). Academic Press, San Diego, pp247-261, 2002.

3. Peehl DM: Primary cell cultures as models of prostate cancer development. Endocr Relat Cancer 12: 19-47, 2005.

4. Tran CP, Lin C, Yamashiro J and Reiter RE: Prostate stem cell antigen is a marker of late intermediate prostate epithelial cells. Mol Cancer Res 1: 113-121, 2002.

5. Coffey RN, Watson RW, Hegarty PK, Watson CL, Wolohan L, Brady HR, O'Keane C and Fitzpatrick JM: Priming prostate carcinoma cells for increased apoptosis is associated with upregulation of the caspases. Cancer 92: 2297-2308, 2001.

6. Peehl DM: Are primary cultures realistic models of prostate cancer? J Cell Biochem 91: 185-195, 2004.

7. Lang SH, Stark M, Collins A, Paul AB, Stower MJ and Maitland NJ: Experimental prostate epithelial morphogenesis in response to stroma and three-dimensional matrigel culture. Cell Growth Differ 12: 631-640, 2001

8. Hall JA, Maitland NJ, Stower M and Lang SH: Primary prostate stromal cells modulate the morphology and migration of primary prostate epithelial cells in type 1 collagen gels. Cancer Res 62: 58-62, 2002.

9. Cunha GR, Hayward SW, Wang YZ and Ricke WA: Role of the stromal microenvironment in carcinogenesis of the prostate. Int J Cancer 107: 1-10, 2003.

10. Barclay WW, Woodruff RD, Hall MC and Cramer SD: A system for studying epithelial-stromal interactions reveals distinct inductive abilities of stromal cells from benign prostatic hyperplasia and prostate cancer. Endocrinology 146: 13-18, 2005. 
11. Zwergel T, Kakirman H, Schorr H, Wullich B and Unteregger G: A new serial transfer explant cell culture system for human prostatic cancer tissues preventing selection toward diploid cells. Cancer Genet Cytogenet 101: 16-23, 1998.

12. Castellon E, Venegas K, Saenz L, Contreras H and Huidobro C: Secretion of prostatic specific antigen, proliferative activity and androgen response in epithelial-stromal co-cultures from human prostate carcinoma. Int J Androl 28: 39-46, 2005.

13. Bonkhoff H, Stein U and Remberger K: Multidirectional differentiation in the normal, hyperplastic, and neoplastic human prostate: simultaneous demonstration of cell-specific epithelial markers. Hum Pathol 25: 42-46, 1994.

14. Garraway LA, Lin D, Signoretti S, Waltregny D, Dilks J, Bhattacharya $\mathrm{N}$ and Loda $\mathrm{M}$ : Intermediate basal cells of the prostate: in vitro and in vivo characterization. Prostate 55: 206-218, 2003.

15. Uzgare $\mathrm{AR}, \mathrm{Xu} \mathrm{Y}$ and Isaacs JT: In vitro culturing and characteristics of transit amplifying epithelial cells from human prostate tissue. J Cell Biochem 91: 196-205, 2004.

16. Festuccia C, Angelucci A, Gravina GL, Muzi P, Miano R, Vicentini $\mathrm{C}$ and Bologna $\mathrm{M}$ : Epithelial and prostatic marker expression in short-term primary cultures of human prostate tissue samples. Int J Oncol 26: 1353-1362, 2005.

17. Festuccia C, Angelucci A, Gravina GL, Muzi P, Vicentini C and Bologna M: Effects of 5 alpha reductase inhibitors on androgendependent human prostatic carcinoma cells. J Cancer Res Clin Oncol 131: 243-254, 2005.
18. Gravina GL, Festuccia C, Millimaggi D, Tombolini V, Dolo V, Vicentini $\mathrm{C}$ and Bologna $\mathrm{M}$ : Bicalutamide demonstrates biologic effectiveness in prostate cancer cell lines and tumor primary cultures irrespective of Her2/neu expression levels. Urology 74: 452-457, 2009.

19. Nanni S, Priolo C, Grasselli A, D'Eletto M, Merola R, Moretti F, Gallucci M, De Carli P, Sentinelli S, Cianciulli AM, Mottolese M, Carlini P, Arcelli D, Helmer-Citterich M, Gaetano C, Loda M, Pontecorvi A, Bacchetti S, Sacchi A and Farsetti A: Epithelialrestricted gene profile of primary cultures from human prostate tumors: a molecular approach to predict clinical behavior of prostate cancer. Mol Cancer Res 4: 79-92, 2006.

20. Kirschenbaum A, Liu XH, Yao S, Narla G, Friedman SL, Martignetti JA and Levine AC: Sex steroids have differential effects on growth and gene expression in primary human prostatic epithelial cell cultures derived from the peripheral versus transition zones. Carcinogenesis 27: 216-224, 2006.

21. Peehl DM, Shinghal R, Nonn L, Seto E, Krishnan AV, Brooks JD and Feldman D: Molecular activity of 1,25-dihydroxyvitamin D3 in primary cultures of human prostatic epithelial cells revealed by cDNA microarray analysis. J Steroid Biochem Mol Biol 92: 131-141, 2004.

22. Rose A, Xu Y, Chen Z, Fan Z, Stamey TA, McNeal JE, Caldwell $\mathrm{M}$ and Peehl DM: Comparative gene and protein expression in primary cultures of epithelial cells from benign prostatic hyperplasia and prostate cancer. Cancer Lett 227: 213-222, 2005. 